\title{
Study on risk assessment of prefabricated construction supply chain based on AHP
}

\author{
Li keda ${ }^{1, *}$ and Zhu, weiwei ${ }^{1}$ \\ ${ }^{1}$ Shenyang Jianzhu University School of Management, Shenyang, China
}

\begin{abstract}
According to the national "14th Five-Year Plan", the goal of supply chain is to upgrade the industrial supply chain. This paper conducts research on the supply chain risks of prefabricated buildings. By identifying the risks in the supply chain of prefabricated buildings, an index system of the supply chain of prefabricated buildings is constructed, and the risk assessment of the supply chain of prefabricated buildings is conducted through AHP. This paper proposes risk response strategies for external risks, planning, procurement, manufacturing, transportation, and delivery.
\end{abstract}

\section{Introduction}

According to the "14th Five-Year Plan", the goal of the supply chain is to adhere to independent control, safety and efficiency, do a good job in the strategic design and precise implementation of supply chain by industry, and promote the optimization and upgrading of the whole industrial chain. Since 2016, the government has vigorously promoted the development of prefab buildings. With the development of prefab buildings, domestic and foreign scholars have conducted extensive studies on prefab buildings, but relatively few studies have focused on the supply chain risks of prefab buildings. This paper starts from the risk identification of prefabricated supply chain, and uses the evaluation method of AHP to carry out weight calculation for the prefabricated building risk and evaluate the risk. Finally, according to the degree of risk put forward to deal with the risk of suggestions.

\section{Construction of prefabricated building supply chain risk index system}

\subsection{Supply chain risk identification of prefabricated buildings}

In order to effectively identify the risk factors of the prefabricated building supply chain, it is necessary to identify the hazard sources first, and then list the risk factors of the prefabricated building supply chain in a more comprehensive way after determining the hazard sources. By classifying and analyzing the sources of supply chain risks, it is found that the classification can be divided into different categories according to the application scope and analysis perspective of the supply chain, but the ultimate purpose is to comprehensively and systematically identify the supply chain risks by analyzing the sources of risks. Based on previous research results and analysis of supply chain structure of industrial construction projects, this paper, from the perspective of owners, divides the supply chain risk sources of prefabricated construction projects into two categories: external environmental risk based on engineering supply chain and internal risk based on engineering supply chain. ${ }^{[1]}$

(1) Risk factors of external environment of prefabricated buildings based on engineering supply chain are generally affected by changes in natural environment and policies and regulations. Macroeconomic turbulence and political and social reasons, even if the project itself will not change because of these influencing environmental factors, when it happens the risk factors, however, supply chain operation may affect and even cause the supply chain, finally, it hinders the realization of project schedule, cost, safety, quality and other objectives.

(2) Based on the project risk source of prefabricated building project internal supply chain operation in whole life cycle of industrial construction projects including project planning, design and planning, project procurement and preparation of project construction, project delivery, operations, such as different stages, each stage involves different stakeholders, the stakeholders is the node enterprises of supply chain of industrialization construction projects, The internal operation of the assembly building supply chain is supported by the cooperation between these nodal enterprises. Internal risk factors are mainly from planning, procurement, manufacturing, transportation and delivery.

*Corresponding author: 17662858806@163.com 


\subsection{Prefabricated building supply chain risk assessment index system}

According to the external and internal risks of the assembly building supply chain mentioned above, the risk factors of external risks include natural environment risk, policy and regulation risk, macroeconomic risk, political and social risk. Internal risks include planning, procurement, manufacturing, transportation and delivery, which also include specific factors.

(1) The influencing factors of planning risks are unreasonable supply chain structure, inaccurate formulation of strategic plans and lack of information sharing mechanism.

(2) The influencing factors of procurement risk are unreasonable procurement plan, high purchase price of components and high inventory cost of components.

(3) The influencing factors of manufacturing risk are low standardization degree of component design, project quality, project cost and project duration.

(4) The influencing factors of transportation and delivery risk are unqualified engineering subcontracting, reliability of logistics company and on-time delivery rate.

\section{Construction of prefabricated building supply chain risk assessment model}

\subsection{Establishment of hierarchical structure model}

The Analytic Hierarchy Process (AHP) is a multi-level system analysis model that decomposes the complex system into several different factors. Then, targets are allocated and weights are calculated. Finally, a hierarchical structure model can be established by ranking the risk index system of prefab building supply chain. The model is divided into the top - target layer, the middle - criterion layer and the lowest - index layer.

\subsection{Construction of judgment matrix}

The key of analytic hierarchy process is to construct judgment matrix. Satie's 9 importance grades and their assigned values are used to compare the relative importance of the two indicators of the subordinate factors covered in the same superior index. The scale of proportional values is shown in Table 1.

Table1Meaning of Scale Values

\begin{tabular}{cc}
\hline Scale values & Importance comparison \\
\hline 1 & Equally important \\
3 & Bi factor was slightly stronger than $\mathrm{Bj}$ factor \\
7 & $\mathrm{Bi}$ factor was stronger than $\mathrm{Bj}$ factor \\
9 & Bi factor was significantly stronger than $\mathrm{Bj}$ factor \\
The above judgment is located between the intermediate state corresponding to the scale value is $2,4,6,8$ \\
If the reciprocal is compared between Bi factor and $\mathrm{Bj}$ factor, the judgment value is aji=1/aij, aii=1
\end{tabular}

The experts who constructed the index system were invited to construct the judgment matrix of the criterion layer relative to the overall target layer and the judgment matrix of the index layer to the criterionlayer, and the judgment matrix was constructed through the advice of the experts.

\subsection{Consistency test}

Satie defined the consistency index CIto check that the consistency of thinking is determined by Equation 1 when constructing the matrix

$$
C I=\frac{\lambda_{\text {max }}{ }^{-} n}{n-1}
$$

The CI value is inversely proportional to the consistency of the judgment matrix. The larger the CI value is, the worse the consistency is. Usually, the condition for the judgment matrix to pass the consistency test is that the smaller the CI, the better. In order to measure the consistency of the judgment matrix more reasonably, Satie constructed the consistency ratio CR for detection through the random consistency index RI (Table 2).

Table 2 Values of Ri of different orders

\begin{tabular}{llllllllll}
\hline Order number $\mathrm{n}$ & 1 & 2 & 3 & 4 & 5 & 6 & 7 & 8 & 9 \\
$\mathrm{RI}$ & 0.00 & 0.00 & 0.58 & 0.90 & 1.12 & 1.24 & 1.32 & 1.41 & 1.45 \\
\hline
\end{tabular}

The ratio of the consistency index CI of the judgment matrix to the average random consistency index $\mathrm{Ri}$ of the same order is called the random consistency ratio, denoted as CR, see Equation 2.

$$
C R=\frac{C I}{R I}
$$

Similarly, when the judgment matrix passes the consistency test, the condition is $\mathrm{CR} \leq 0.1$, then its normalized eigenvector can be taken as the weight vector The $\mathrm{Cr}$ values of each matrix are as follows: $\mathrm{CR}(\mathrm{A})=$ 0.0336; $\mathrm{CR}(\mathrm{B} 1)=0.1 ; \mathrm{CR}(\mathrm{B} 2)=0.032 ; \mathrm{CR}(\mathrm{B} 3)=0.032$; $\mathrm{CR}(\mathrm{B} 4)=0.043 ; \mathrm{CR}(\mathrm{B} 5)=0.032$. All the six matrices passed the single-layer consistency detection. The weight of the target layer relative to the criterion layer and the criterion layer relative to the target layer were calculated successively. Finally, the weight of the index layer relative to the target layer was obtained. ${ }^{[2]}$ 


\subsection{Total ranking of levels}

According to the calculation of hierarchical analysis, can calculate the total weight of the target layer, the weight, weight is in the top eight $\mathrm{C} 12$, project quality, $\mathrm{C} 8$ purchasing plan is not reasonable, $\mathrm{C} 13$ project cost, C15engineering subcontract is unqualified, C5supply chain structure is not reasonable, C9component purchase price is high, the reliability of the C14project period, C16 logistics company.

Table 3 Calculation of total weight in AHP

\begin{tabular}{|c|c|c|c|c|c|}
\hline Target layer & $\begin{array}{l}\text { Rule } \\
\text { layer }\end{array}$ & $\begin{array}{l}\text { Criteria } \\
\text { weights }\end{array}$ & Index layer & $\begin{array}{c}\text { Index } \\
\text { layer } \\
\text { weight }\end{array}$ & $\begin{array}{c}\text { Target } \\
\text { total } \\
\text { weight }\end{array}$ \\
\hline \multirow{17}{*}{$\begin{array}{l}\text { Prefabricate } \\
\text { d building } \\
\text { supply chain } \\
\text { risk } \\
\text { assessment }\end{array}$} & \multirow{4}{*}{$\begin{array}{c}\text { B1-Ext } \\
\text { ernal } \\
\text { risks }\end{array}$} & \multirow[t]{4}{*}{0.047} & C1 Natural environmental risks & 0.0559 & 0.0026 \\
\hline & & & C2 Policy and Regulatory Risks & 0.2355 & 0.011 \\
\hline & & & C3 Macroeconomic risks & 0.1359 & 0.0064 \\
\hline & & & C4 Political and social risks & 0.5727 & 0.0269 \\
\hline & \multirow{3}{*}{$\begin{array}{c}\text { B2-Pla } \\
\text { n risk }\end{array}$} & \multirow[t]{3}{*}{0.1078} & C5The structure of supply chain is unreasonable & 0.637 & 0.0687 \\
\hline & & & C6The strategic plan is incorrectly formulated & 0.105 & 0.0113 \\
\hline & & & C7 lacks a mechanism to share information & 0.258 & 0.0278 \\
\hline & \multirow{3}{*}{$\begin{array}{l}\text { B3-Pro } \\
\text { cureme } \\
\text { nt risk }\end{array}$} & \multirow[t]{3}{*}{0.2557} & $\mathrm{C} 8$ procurement plan is not reasonable & 0.637 & 0.1629 \\
\hline & & & C9The purchase price of components is high & 0.258 & 0.066 \\
\hline & & & C10 component inventory cost is high & 0.105 & 0.0268 \\
\hline & \multirow[t]{4}{*}{$\begin{array}{l}\text { B4-Cre } \\
\text { ate risk }\end{array}$} & \multirow[t]{4}{*}{0.4701} & $\begin{array}{c}\text { C11 The standardization degree of component } \\
\text { design is low }\end{array}$ & 0.055 & 0.0258 \\
\hline & & & C12 Project quality & 0.5638 & 0.265 \\
\hline & & & C13 Project Cost & 0.2634 & 0.1238 \\
\hline & & & C14 Project duration & 0.1178 & 0.0554 \\
\hline & \multirow{3}{*}{$\begin{array}{l}\text { B5-Tra } \\
\text { nsport } \\
\text { and } \\
\text { deliver } \\
\text { y risks }\end{array}$} & \multirow[t]{3}{*}{0.1194} & C15 project subcontracting unqualified & 0.637 & 0.0761 \\
\hline & & & C16 logistics company reliability & 0.258 & 0.0308 \\
\hline & & & $\mathrm{C} 17$ on time delivery rate & 0.105 & 0.0125 \\
\hline
\end{tabular}

\section{Suggestions on supply chain risks of prefabricated buildings}

\subsection{External risk coping strategies}

Risk factors include external risks of natural environment, policy risks, macroeconomic risks, political and social risks. The frequency of natural disasters such as earthquake, flood, climate change and other natural disasters varies in different areas of the project. Therefore, hydrological and climatic conditions of the project site selection should be understood in the early stage of the project. Develop contingency plans for natural disasters in advance to minimize increased costs and losses due to adverse climate impacts. National policies guide the development direction of all walks of life, so enterprises need to carefully study the national laws and regulations, the construction cycle is long, the economic environment fluctuates greatly, it is necessary to develop coping strategies in advance, to prevent changes in the economic environment. Attention should also be paid to political and social changes. Since the government's planning and social emergencies will affect the changes of the supply chain, we should have an early warning attitude towards these changes and pay attention to the national planning in advance. Although the probability of unexpected events is very small, we should also have a warning psychology. The best way to deal with this situation is to buy engineering insurance. Risk reduction through insurance claims. ${ }^{[3]}$

\subsection{Plan risk response strategies}

The influencing factors of planning risk are the unreasonable structure of supply chain, the inaccurate formulation of strategic plan and the lack of information sharing mechanism. As a construction supply chain with a wide spread, many subjects and complex properties, the "bullwhip effect" of information error often causes unnecessary workload and cost increase, which may seriously lead to the interruption of the supply chain. It is beneficial to improve the accuracy and authenticity of information transmission and strengthen the accuracy and consistency of the plan to set up an information management platform together with the main participants of the supply chain. Increase the sharing of information between parties, thereby reducing losses. The unreasonable structure of the construction supply chain has the greatest impact on the planning risk, and even leads to the interruption of the construction supply chain and its failure to operate normally. Therefore, it is necessary to carry out process analysis and reorganization of the construction supply chain. In the analysis of assembly building supply chain, attention should be paid to the most easily interrupted links, such as design, procurement, construction and so on. If there is a problem in a certain link, it is necessary to take emergency measures in time, and immediately coordinate with other enterprises in the supply chain node to provide help. 


\subsection{Procurement risk response strategy}

The influencing factors of purchase risk are unreasonable purchase plan, high purchase price of component and high inventory cost of component. According to these factors, a long-term and stable partnership is beneficial to the continuous and stable operation of the assembly building supply chain network. At present, the construction industry is still in the stage of one-time supply chain. The temporary supply and demand relationship of supply chain subjects means that the supply chain will be removed when the project is delivered and completed. Compared with traditional construction, prefabricated construction projects can better test their professional skills. With only temporary supply chain partners, the main body of the supply chain often changes, and the fluctuation of the supply chain is inevitable. To maintain the long-term stability of the relationship between the construction parties, a long-term and stable prefabricated concrete construction supply chain is formed jointly by several fixed and reliable friends and businessmen. Establish a supplier database, put the excellent suppliers with cooperation intention into the database and conclude the priority cooperation agreement, so that all parties can advance and advance together for win-win cooperation; The establishment of supplier blacklist and the blacklist of suppliers with insufficient ability and poor credit will play an important role in the procurement risk control of precast concrete building supply chain.

\subsection{Manufacturing risk coping strategies}

Low standardization degree of parts design, engineering quality, engineering cost and engineering duration are the influencing factors of manufacturing risk. By establishing a good working relationship with various subcontractors, contractors can reduce the risk of "late delivery", facilitate design optimization, avoid wasting time and cost due to excessive changes, and reduce the risk of delayed design approval. The general contractor should also strengthen the construction organization and management by selecting the designers and project management personnel with better technical level, fully evaluating the project and selecting the appropriate construction scheme. In terms of construction period, we choose leading groups with excellent management ability and experienced professional construction teams, strictly implement the post responsibility system, and comprehensively guarantee the total construction period from multiple perspectives such as system and plan. In terms of labor cost control, for a single project with low technical content, professional subcontracting is adopted to control the work. For the project with complex technology, the construction should be reasonably organized and personnel input should be optimized. In the mechanical cost control, reasonable organization and scheduling, pay attention to a machine multi-purpose. Material cost accounts for about $60 \%$ of the project cost. Want the price that controls material strictly and use, if execute norm to get material system, make material gets make full use of, reduce the waste of material as far as possible. At the same time, personnel management should be strengthened to avoid the increase of material cost caused by human factors. We will improve construction techniques and popularize new technologies and processes that consume less resources. ${ }^{[4]}$

\subsection{Transportation and delivery risk responsestrategy}

Establish a sound project information management system, collect data timely and accurately in the process of project implementation, strengthen the sorting of data on cost and contract changes, and form a complete handover data at the end of the project. Risk management personnel should be assigned to the project, and the risk management system should be implemented, so that risk factors can be accurately captured before the occurrence of risks. When risks occur, there should be complete countermeasures. In addition, risk management objective assessment and reward and punishment system should be set up, so as to enhance the risk awareness of personnel. In the link of project acceptance, reasonable acceptance personnel shall be selected and those who have interests with the contractor shall be excluded to ensure that the whole acceptance work is objective and fair.

\section{Conclusion}

Based on the research on the supply chain risk of prefabricated buildings in this paper, the important risks of the supply chain of prefabricated buildings are evaluated from the three steps of risk identification, risk assessment and risk prevention, and the risk countermeasures are proposed for the external, planning, procurement, manufacturing, transportation and delivery of the supply chain of prefabricated buildings. This paper provides solutions to reduce prefabricated building supply chain risks

\section{References:}

1. Li Naixu. Study on Supply Chain Risk Early Warning of Industrial Construction Project [D]. Xi 'an University of Architecture and Technology, 2020.

2. Jiang Xin, Sun Zhengxi, Xu Ping, Wu Yuanli, Li Hongming. Hydropower project group of the supply chain risk assessment research [J]. The people of the Yangtze river, 2016, 47 (6): 78-81 + 91.DOI: 10.16232 / j.carol carroll nki.1001-4179.2016.06.017

3. Xu Yongge, Chen Xinran, Li Ran. Research on risk management of engineering project supply chain [J]. Hydropower, 2018, 44(08): 87-90+100.

4. Wang Guotao, He Lina. Supply Chain Risk Management Based on Hesitation Fuzzy Dematel and Risk House [J/OL]. Computer Integrated Manufacturing Systems :1-18[2020-08-20 16:41]. 